\title{
Bioética y derecho a decidir sobre el propio cuerpo, sus extensiones, productos y derivados: el discutible caso de las células HeLa
}

Bioethics and the right to decide over your own body, their extensions, products and derivatives: the controversial HeLa cells case

\author{
Carmen A. Cardozo-de Martínez MSc', \\ Patricia D. Sorokin PhD², Maria Angélica Sotomayor $\mathrm{MSc}^{3}$
}

\begin{abstract}
Resumen: la investigación con células de origen humano y animal fue incorporada en la ciencia hace más de un siglo y su uso, tan cotidiano, no había merecido cuestionamiento alguno acerca de sus implicaciones éticas, legales y sociales por parte de la comunidad científica pues se asumía que era inocuo e impersonal. La información genética evidencia comportamientos biológicos individuales o colectivos de sus grupos familiares o generaciones, situación que puede transgredir la confidencialidad y el derecho a la privacidad de las personas y sus familias. El caso de la investigación con células HeLa constituye un modelo de interpretación del ethos científico que requiere ser abordado desde un enfoque interdisciplinario, con una perspectiva de derechos humanos y bajo una redefinición de los conceptos legales, sociales y éticos del cuerpo humano, la salud, la enfermedad y la vida, a fin de garantizar la efectiva protección de los derechos personales fundamentales.
\end{abstract}

Palabras clave: dignidad humana, investigación, derechos humanos, derechos del paciente, violaciones de los derechos humanos, discusiones bioéticas.

Abstract: The use of human and animal cells in research was incorporated into scientific processes more than one century ago, and due its daily use it had not aroused any questioning about their ethical, legal, and social implications by the same researchers because its use was considered as innocuous and impersonal. The genetic information realizes the biological behavior of people individually and collective of their familiar groups and generations, situation that can transgress the confidentiality, privacy, and the right to privacy of individuals and their families. HeLa cell research constitutes a model of interpretation of the scientific community against the personal and familiar rights that must be studied from an interdisciplinary approach, from an human rights perspective and with a redefinition of legal, social and ethical concepts of human body, health, disease and life, to ensure the effective protection of fundamental personal rights.

\footnotetext{
'Odontóloga, MSc en Periodoncia, Fogarty International Scholar en Ética en Investigación Biomédica y Psicosocial, OPS/OMS, Universidad de Chile. Profesora Universidad de Chile. Santiago, Chile. Correo electrónico: carmen_aliciademartinez@yahoo.co.uk ${ }^{2}$ Licenciada en Ciencias de la Educación, Especialista en la Problemática del Uso Indebido de Drogas, MSc en Salud Pública, MSc en Bioética, PhD en Ciencias Sociales. Docente-Investigadora, Universidad de Buenos Aires (UBA). Buenos Aires, Argentina. ${ }^{3}$ Licenciada en Ciencias Jurídicas y Sociales, MSc en Derecho de Seguridad Social. Docente invitada Universidad de Chile y Universidad Andrés Bello. Santiago, Chile.
}

Conflicto de intereses: las autoras declaran que no tienen conflicto de intereses

Medicina \& Laboratorio 2015; $21: 565-578$

Módulo 28 (Artículos de Reflexión), número 2. Editora Médica Colombiana S.A. $2015^{\circ}$

Recibido el 01 de diciembre de 2015; aceptado el 19 de diciembre de 2015

Medicina \& Laboratorio Volumen 21, Números II-12, 2015. 
Key words: Personhood; research, human rights, patient rights, human rights abuses, bioethical issues.

Cardozo-de Martínez CA, Sorokin PD, Sotomayor MA. Bioética y derecho a decidir sobre el propio cuerpo, sus extensiones, productos y derivados: el discutible caso de las células HeLa. Medicina \& Laboratorio 2015; 21: 565-578.

E 195I, con 31 años, Henrietta Lacks (véase figura I) fue ingresada en el Hospital Johns Hopkins en Baltimore, Estados Unidos, con un fuerte dolor abdominal, acompañado de hemorragias frecuentes, diagnosticada con cáncer de cuello uterino, tan avanzado y agresivo, que nada pudo hacerse. Durante su agonía el médico ginecólogo e investigador George Otto Gey extrajo células que obtuvo a partir del tejido tumoral de la biopsia sin que mediara conocimiento ni consentimiento de ella ni de su familia [I].

Tras someter las muestras a investigación se desarrolló el primer cultivo in vitro de células humanas [2], marcando así un hito en la historia científica y comprobando que tales células tenían una capacidad de replicación nunca antes vista, con características de «inmortales». Así fue como se generó la línea celular denominada HeLa (véase figura 2), por las iniciales del nombre "Henrietta» y su apellido de casada «Lacks», que ha dado lugar al desarrollo de investigaciones por más de 60 años y a la puesta en bases de datos de consulta pública de su genoma completo, en el año 2013 [3]

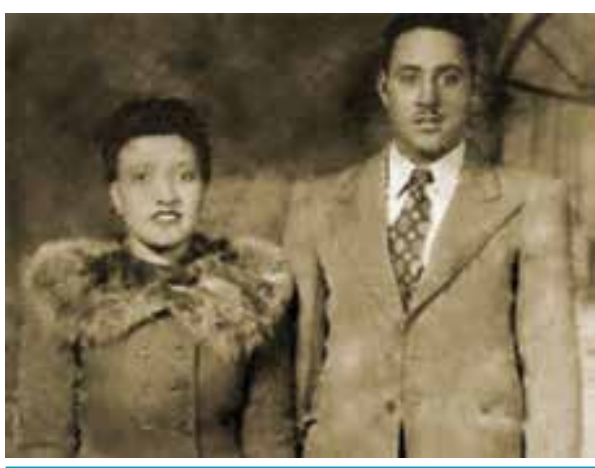

Figura I. Henrietta Lacks (izquierda). Tomado de Wikimedia Commons. Creative Commons-Public Domain.

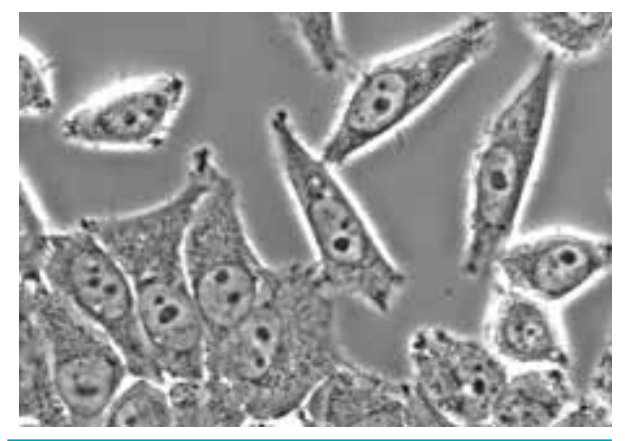

Figura 2. Línea celular HeLa. Tomada de "HELA-Zellen" por Paul Anastasiadis, Instituto Fraunhofer de Ingeniería Biomédica, Sankt Ingbert, Alemania. Creative Commons-BY-SA 3.0. Con anterioridad y frente a la espectacularidad del hallazgo científico, la información clínica de la paciente y de su vida privada fue ampliamente divulgada, no así su identidad; además, ha sido asociada al desarrollo biotecnológico [4] gracias a los avances logrados desde 1943 con la propagación en el laboratorio de los fibroblastos de ratón (células propias de los tejidos de soporte del cuerpo humano), que permitieron que, con la propagación o multiplicación indefinida de las células Hela [5], a gran escala y con fines de producción industrial, se pudieran desarrollar vacunas y los diversos productos que posteriormente obtuvieron diversas empresas para el beneficio humano [6].

El caso de las células HeLa ha producido a la fecha aproximadamente 50 toneladas de células para investigación [7], así como innumerables desarrollos biotecnológicos con más de once mil patentes, producción de medicamentos fundamentales contra el cáncer, la leucemia y la enfermedad de Parkinson y más de sesenta mil publicaciones científicas a lo largo del mundo, 
lo que claramente ha significado un gran avance científico, técnico asistencial y económico, lejos de toda consideración con la persona de quien son una parte integral por contener toda la información genética, con la familia que se ve afectada por el público conocimiento de aspectos personales y familiares que deberían ser privados y con sus descendientes [8], quienes igualmente reciben los efectos. En este manuscrito se plantean los conflictos de carácter ético, jurídico y social en torno a los desarrollos científicos obtenidos a partir del cuerpo humano, sus partes y derivados de ellas, en un nuevo contexto de significación que implica igualmente una resignificación de la ciencia como sensible y humana en cuanto a su relación con la obtención de la información.

\section{Sentencias recientes, doctrina, células madre}

Mucho se ha escrito ya sobre la ausencia de reglamentación de carácter jurídico en muchos países que garantice efectivamente el derecho a la privacidad, la información y la confidencialidad, y el respeto a toda forma de vida, considerando a la persona completa constituida por el cuerpo biológico, alejado de la mente y la cultura. Bergel (2013) [9] sostiene que:

Si el cuerpo en su integridad está fuera del comercio, ¿con qué argumentos podría sostenerse que una parte separada por el solo efecto de su segregación pierde el carácter que se le atribuye al todo? No obstante la razonabilidad de esta postura, lo cierto es que cada vez con más intensidad podemos observar cómo las partes separadas del cuerpo han ingresado al mercado.

Esta situación, tratándose de las células HeLa, plantea un caso paradigmático.

Se percibe, por parte de los artistas y sociólogos, cómo las células son una extensión viva del cuerpo, es decir, una permanencia en el tiempo de una persona y sus cualidades genéticas [10]. Un análisis retrospectivo de las células HeLa muestra la ausencia de cuestionamiento ético respecto a su uso, así como el hecho de que previo a que fueran extraídas para fines distintos a los meramente diagnósticos [I l] ni la donante ni su familia recibieron ningún tipo de explicación. Si bien, es necesario contextualizar las circunstancias histórico-políticas del suceso, nótese que quizá debido a que por ser mujer, afroamericana y perteneciente a un estrato socioeconómico bajo a Henrietta se la ubicó en una situación de extrema vulnerabilidad, entendiendo como vulnerable a aquella persona o al colectivo de personas fragilizadas, tanto jurídica como políticamente, en la promoción, protección y garantía de sus derechos ciudadanos. Por otro lado, a sus familiares tampoco se les otorgó un beneficio posterior devenido de la investigación, el desarrollo, la innovación y el crecimiento empresarial logrado gracias a las células iniciales.

Pese a que la casualidad inicial de tal hallazgo científico pudo haber retrasado dicho cuestionamiento y debate, el avance ético y el surgimiento de la Bioética en las décadas posteriores habría requerido nuevas decisiones y compensaciones conforme las Pautas Éticas Internacionales para la Investigación Biomédica en los Seres Humanos [12]. Este ajuste se justifica también ya que, aunque tales pautas fueron publicadas en el año 2002, casi cincuenta años después de lo sucedido, cabe preguntarse si dicho "avance científico» se habría logrado sin la participación de las personas, sus cuerpos, células y todo el material asociado a ellas [13]. Por otra parte, a pesar de que hoy día es impensable obtener tejido de una persona en la forma en que ocurrió en este caso paradigmático [14], los avances beneficiosos del conocimiento a partir de dicho 
material y del desarrollo obtenido continúan. Se requiere entonces que en esta fase se produzca un «ajuste» ético sobre la base del respeto a la dignidad humana, los derechos humanos y las libertades fundamentales. Se requiere igualmente una resignificación social del cuerpo, sus partes y las extensiones del mismo pues se ve en la práctica que partes del ser perviven en los laboratorios a través del tiempo.

\section{Ciencia, ética y sociedad}

Desde finales de la Segunda Guerra Mundial, hasta nuestros días, las relaciones entre la ciencia y la sociedad han estado mediadas por la intensificación de las conexiones recíprocas entre ciencia, mundo industrial, opciones comerciales y orientaciones políticas y militares [I5]; situación que ha modificado tanto la dinámica como la estimación valórica del quehacer científico [16]. El valor terapéutico de muchos de los productos del avance científico desvió la posibilidad de buscar nuevas opciones a la comprensión del fenómeno salud-enfermedad humana [17], concentrándola en el encuentro de hallazgos cada vez más lejanos al ojo humano, sustentados fuertemente en la tecnología.

La búsqueda continua de nuevos desarrollos e invenciones, para patentar y generar nichos de rendimiento económico, ha introducido una nueva racionalidad en las instituciones que hacen investigación, principalmente las universidades, donde la confidencialidad y la reserva propias del proceso de patentamiento ha producido a su vez nuevos códigos de ética dirigidos, esta vez, a la protección de los creadores y su invento, lo que implica evitar que el conocimiento se disemine sin dejar de cumplir con los propósitos productivos previamente estipulados [18]. Estos nuevos códigos han implicado también un cambio en el sentido y razón de ser de las universidades, ahora centradas en criterios de competencia y producción de profesoresinvestigadores que se «miden» sobre la base de la generación y el patentamiento de productos «redituables», siendo dichos rendimientos económicos aquello que más y mejor contribuye a la supervivencia de sus propias instituciones [19].

En este sentido, aun considerando el tiempo transcurrido, el principal conflicto ético que plantea el caso de las células HeLa es que a Henrietta o a las Henriettas futuras se les sustraiga la posibilidad de conocer los detalles sobre el procedimiento que les afecta y de decidir libremente acerca de su cuerpo, incluidas sus células, frente a los propósitos de ciertos investigadores que hacen prevalecer la racionalidad económica por encima del desarrollo humano [14], en aras de obtener un supuesto éxito científico traducido en la adquisición de bienes materiales y no en el mejoramiento de la calidad de vida ni de la consecución de la felicidad, satisfacción o bienestar de personas como Henrietta y su familia.

Claramente la situación de las células HeLa se podría replicar hoy en el medio científico si las capacitaciones en el campo de la ética de la investigación sólo estuvieran orientadas a cumplir con la formalidad de obtener «un papel» que habilite para seguir investigando, si los miembros de los comités de ética no verificaran que para cada procedimiento se solicite un nuevo consentimiento que explicite cuál será el uso presente y futuro de esa información y si los entes regulatorios estuvieran tan sobrecargados de trabajo y faltos de personal que se les «escaparan» situaciones como esta [20]. 
Tal vez lo que habría que recuperar, o mejor resignificar, es el sentido de la ciencia como sensible y humana o humanitaria, es decir, una ciencia basada en los valores humanos que propenda constantemente por el respeto a los seres vivos y su sentido de la vida [2 I]. En otras palabras, lograr que realmente la ciencia sea parte integral de la sociedad y no un mundo aparte impregnado de normas de carácter técnico, aunque ello implica necesariamente la conceptualización y construcción de un ethos científico como condición sine quanon de la existencia y validez de la ciencia. Tomando como base el preámbulo de la Declaración Universal de Bioética y Derechos Humanos de la UNESCO (2005) que considera «conveniente elaborar nuevos enfoques de la responsabilidad social para garantizar que el progreso de la ciencia y la tecnología contribuye a la justicia y la equidad (...)» [22]; cabe cuestionarse entonces sobre cuál es el límite éticamente aceptable entre «avanzar» en pos de un «desarrollo científico» y «explotar» sujetos, avasallando sus derechos humanos al no reconocer su dignidad intrínseca.

Según propone la UNESCO, la dignidad humana, la libertad, los derechos humanos y la justicia se incluyen en el respeto a la diversidad cultural, el pluralismo y los principios de solidaridad, equidad, cooperación y de responsabilidad con la naturaleza [22]. Por esto, como afirma Hoyos (2005) [23], se consideran principios derivados de los anteriores el de la primacía de la persona, la no discriminación, la autonomía y la responsabilidad, el consentimiento informado, la privacidad y la confidencialidad, así como la obligación de compartir equitativamente los beneficios de la investigación, al hacer referencia a la consideración y reconocimiento del otro como sujeto autónomo y a quien se le asume como digno de merecimiento por su condición única e irrepetible de manera holística. Por ello, en investigación se debe considerar a las personas, sus familias y comunidades de manera integral, incluyendo todos los aspectos y situaciones que hagan relación a los valores descritos. Si la persona y su dignidad humana priman sobre cualquier interés en investigación, entonces es deber del investigador considerar cualquier opción de protección de la persona de aquello que la pueda lesionar en sus intereses biológicos, sociales, personales, religiosos y morales.

En consecuencia cabe preguntarse ¿es moralmente aceptable el uso de células humanas para la investigación cientíica sabiendo que forman parte integral de un todo igualmente social, sensitivo y trascendente? La respuesta a este interrogante requiere dilucidar cuestiones previas entre las cuales la más importante es el valor biológico y social de las células y la forma en que estas se obtienen sin dejar de lado el concepto de ser extensiones vivas del cuerpo de la persona de quien han sido tomadas. La disposición del cuerpo, o de una parte del cuerpo humano vivo, es posible siempre que la persona lo haya consentido previamente de manera libre e informada pues, dado que las personas son únicas e irrepetibles, cada una individualmente podrá aceptar o rechazar los destinos inmediatos o futuros de su cuerpo, de sus partes y sus significados, incluidas lógicamente las células. Específicamente, las células son una extensión del cuerpo vital, de una historia, sentimientos y pensamientos de una persona que construyó su imagen frente a ella misma y los demás en una condición intersubjetiva que transformó radicalmente el concepto de vida y muerte [24].

El interrogante siguiente tiene que ver con el propósito respecto del cual y para el cual el sujeto dispuso de esa parte del cuerpo, destino que debe ser respetado, de lo contrario implicaría desviación o engaño, para luego analizar las implicancias del acceso a los datos genéticos obtenidos mediante la potencial vulneración de la privacidad individual y familiar. Cabría aquí 
incorporar el concepto de Gómez (2010) [25] sobre los principios del bioderecho, dentro de los cuales se promueve la prudencia y la heurística del temor en el científico para que le haga actuar siempre sobre la base del adagio hipocrático que sostiene que «lo primero es no dañar»; en este caso, buscando la protección de las personas por sobre cualquier práctica que no reconozca su dignidad. Esto implica necesariamente una postura más abierta y flexible de parte de los investigadores quienes se ven obligados entonces a conocer más al ser humano desde su perspectiva intersubjetiva y no sólo bajo la categoría biológica.

\section{Ciencia-ser humano-empresa}

Durante años se aceptó el concepto de la neutralidad valorativa de la ciencia como parte inherente a su excelencia. En la actualidad, se acepta que la ciencia es subjetiva y por ende obedece a intereses, propósitos y sentimientos del investigador y su equipo, incluso de las instituciones académicas, sanitarias o científicas y los entes financiadores, generando en muchas ocasiones serios casos de conflictos de interés [26], siendo estos, según lo indicó Thompson (1993) [27]:

Un conjunto de condiciones en las cuales el juicio profesional referido al interés primario (bienestar del paciente y validez de la investigación) puede ser influenciado o afectado por intereses secundarios (como por ejemplo, ganancias financieras o búsqueda de prestigio).

Las diversas etapas del desarrollo científico evidencian el paulatino paso de lo macroscópico a lo ultramicroscópico, incluso a la molécula y el átomo. Esta superespecialización se encontraba ligada a un concepto biológico de la enfermedad sin incluir las consideraciones sociales y culturales que están implícitas en todo acto humano y que lo atraviesan. La mirada era, y aún persiste en muchos grupos, reduccionista, tanto desde la perspectiva biológica como genética [17]. De allí que un organismo completo, o aún sin vida, se podría vincular a una persona o ser humano pues al constituir partes integrales del ser arrojan información atinente a la persona y su valoración de los mismos. Contraria a esta situación estas partes y elementos (las células) fueron desvinculándose o despersonalizándose progresivamente. Una biopsia o muestra en el laboratorio se vincula a una patología o a una condición clínica mas no necesariamente a una persona o ser humano con atributos valóricos, sociales o culturales.

Igual situación se fue presentando progresivamente en el escenario clínico al despersonalizar «sujetos» (de hecho y de derecho) para convertirlos en "pacientes» identificables por su "cuadro clínico». La presentación de las células en los bancos o en las cajas de petri de los laboratorios son la muestra más fehaciente de ello, pues no se vincularon con la persona que las tenía como parte de su cuerpo, se asumieron como un insumo con unas potencialidades y no como parte de un ser humano con historia y significado para ella misma, su familia y su grupo humano de desarrollo vital. La anonimización de las muestras, con el fin de garantizar el rigor de los resultados de la investigación, constituyó un elemento más de despersonalización de estas partes del cuerpo, donde alejarlas de su origen condujo necesariamente a una consideración como objetos de estudio y no partes de una persona.

Más aún, en muchos países, la investigación con donantes o sus productos se ha considerado como una en sujetos no humanos y, en muchos de ellos, estos proyectos no requieren presentación ante los comités de ética para su evaluación y aprobación. Esto ha llevado a que se to- 
men fácilmente partes del cuerpo humano para trasplantes, como insumos para los bancos de tejidos o para la generación de empresas biotecnológicas, puesto que si fue un científico quien las había obtenido por los procedimientos desarrollados en su laboratorio entonces eran de su propiedad. Se pensaba, además, que si el paciente no contaba con esta tecnología tampoco podría acceder a esa información que sólo el científico podría darle, ratificando su propiedad sobre estas. Incluso, durante la década de los ochenta uno de los debates científicos giró en torno a la propiedad de las muestras, puesto que se consideraba que las biopsias y los bancos de tejidos eran propiedad de quien las tomaba o las almacenaba [I I].

La resignificación del cuerpo implica un nuevo motivo de reflexión ciudadana en torno a lo que identifica a una persona en sus características físicas, emocionales, afectivas y transcendentales y los mecanismos para su protección, lo que igualmente lleva a nuevas formas de planteamientos jurídicos. De esta manera, la triada investigador-paciente-empresa se presenta hoy como un ámbito en el cual no se comparten intereses ni expectativas, pero que en la práctica deben ir juntas; así, mientras el investigador lucha por sobrevivir en su medio de significados basados en la novedad, la invención y el secreto, el paciente busca su beneficio en el cumplimiento de sus utopías de salud, belleza y larga vida, y la empresa demanda cada vez más sostenibilidad financiera a largo plazo.

Zalaquett (20I I) [28] sostiene que los conflictos de intereses se deben conceptualizar como la existencia de situaciones de riesgo objetivo para los intereses públicos o los intereses de determinado colectivo porque una persona, funcionario público o agente privado, que se encuentra sometida al deber fiduciario de velar por tales intereses mantiene a su vez cargos, intereses o relaciones de carácter privado (excepcionalmente también de carácter público) que le generan el incentivo de favorecer estos en desmedro o por encima de aquellos.

Es importante recordar el emblemático caso de Moore frente Regents, en el cual, tardíamente, se supo que mientras un médico estaba asistiendo a su paciente (el señor Moore) descubrió incidentalmente que sus células producían una cierta sustancia la cual patentó, creyendo hallarse ante un material de valor tanto científico como comercial. Lo más llamativo del asunto (por alejarse en extremo de la ética) fueron los cinco beneficiarios de dicha patente, a saber: el médico, el hospital y el investigador, más un instituto de genética y una compañía farmacéutica [20].

Resulta crucial, entonces, transparentar la cultura organizacional de la institución en la cual se desarrolla la investigación y más aún la cultura organizacional de quien la financia, pues podríamos afirmar que se está trasgrediendo la responsabilidad y la buena conducta científica al permitir la continuidad de estas acciones [29]. La disminución paulatina pero constante de los fondos de las universidades y las complejidades y costos de los procesos de patentamiento internacional, entre otras razones, han llevado a una dependencia cada vez mayor de entes financiadores externos, lo que hace peligrar la neutralidad que por su propia naturaleza debieran mantener las instituciones académicas y de investigación; sin embargo, los investigadores son los que están más expuestos a los riesgos de los entes financiadores puesto que dependen de los intereses de quien maneja los fondos de financiamiento.

La cultura científica de los investigadores también ha impuesto modalidades de trabajo que pueden traspasar la barrera de lo correcto, pero que en la práctica buscan facilitar el devenir investigativo por los vaivenes económicos propios, como es el caso de las células HeLa. Estas 
células inicialmente fueron entregadas como una acción solidaria entre investigadores, para luego convertirse en insumos comerciales. El comportamiento en cultivo de laboratorio de estas células no solamente despertó la curiosidad de los laboratorios de investigación, sino que también posibilitó la visualización de su potencial comercial. Si se podían obtener grandes cantidades de ellas ¿por qué no venderlas?

Los laboratorios de investigación académicos requieren garantizar su mantenimiento y sostenibilidad financiera; en dicho encuadre, el eventual conflicto moral no siempre ha formado parte de su racionalidad investigativa, probablemente debido a que en general a sus integrantes se les ha capacitado en cuestiones regulatorias y financieras más que en los aspectos metodológicos y éticos que se deben considerar con antelación al diseño de un protocolo.

La comunidad científica ha avalado estos comportamientos, sin cuestionárselo de manera amplia y abierta. Ello se evidencia en las múltiples publicaciones, premios y reconocimientos basados en las células HeLa otorgados a sus investigadores a través de la historia [30]. Situación similar se presenta en otros casos de investigación en seres humanos, en los cuales la mirada científica ha distado sustancialmente de la consideración de construcción moral de las relaciones intersubjetivas entre investigador e investigado. A modo de ejemplo pueden citarse, entre otros, los casos Tuskegee y Willowbrook y más recientes, Milgram y Guatemala [3।], siendo una constante la utilización de los sujetos de investigación ("probandos») solo como medios y, por consiguiente, llevando a su «cosificación». Se ha omitido así en ellos la sublimidad y la dignidad como bien insustituible e innegociable de todo ser humano.

\section{Bioética, genética y derechos humanos}

En el año 1997 la UNESCO reconoce en la Declaración Universal sobre el Genoma Humano y los Derechos Humanos al genoma humano como «la base de la unidad fundamental de todos los miembros de la familia humana y del reconocimiento de su dignidad intrínseca y su diversidad», reconocimiento que incluye que «en sentido simbólico, el genoma humano es el patrimonio de la humanidad» [32]. En esta declaración la UNESCO impulsa los principios democráticos de la dignidad, la igualdad y el respeto mutuo de los hombres y plantea que:

La amplia difusión de la cultura y la educación de la humanidad para la justicia, la libertad y la paz son indispensables a la dignidad del hombre y constituyen un deber sagrado que todas las naciones han de cumplir con un espíritu de responsabilidad y de ayuda mutua.

De lo anterior queda claramente excluida la explotación que implica, entre otras cosas, el uso y el abuso de alguien, transformándolo en cosa, en objeto para la obtención de un beneficio ajeno [33].

Es importante resaltar la existencia de otros documentos relacionados como la Declaración Universal de Derechos del Hombre de la Organización de las Naciones Unidas (ONU, 1948) [34], Declaración de las Naciones Unidas sobre la Clonación Humana (2005) [35], el Convenio de las Naciones Unidas sobre la Diversidad Biológica (1992) [36], la Declaración Internacional sobre los Datos Genéticos Humanos (2003) [37], la Declaración Universal sobre Bioética y Derechos Humanos (2005) [22], la Declaración sobre la Ciencia y el uso del saber científico (1999) [38], la Declaración Universal de la UNESCO sobre la Diversidad Cultural 
(200 I) [39] y la Declaración sobre las Responsabilidades de las Generaciones actuales para con las Generaciones Futuras (1997) [40] de la UNESCO, el Código de Nuremberg del Tribunal Internacional de Nuremberg (1946) [33], la Declaración de la AMM sobre el Proyecto Genoma Humano (1992) [4I], la Declaración de Helsinki de la AMM-Principios éticos para las investigaciones médicas en seres humanos (2013) [42] y la Declaración Bioética de Gijón de la Sociedad Internacional de Bioética (2000) [43].

Estos significativos avances se contraponen a visiones como las de Oscar Varsavsky, que en su libro Ciencia, política y cientificismo, publicado en 1969, estableció el calificativo "cientificista» para referirse a aquel «investigador que se ha adaptado a este mercado científico, que renuncia a preocuparse por el significado social de su actividad, desvinculándola de problemas políticos y entregándose de lleno a su 'carrera'» [44]; visión imperante por parte de algunos grupos que renuncian a cualquier consideración que no sea técnica en su investigación para lograr su «perfección» o «idoneidad pura».

La Bioética, a partir de la reflexión y de la deliberación, identifica los conflictos que se presentan en el campo científico y propone cursos de acción para atenuarlos, disminuirlos y, en lo posible, superarlos. En este sentido, es probable que el señalamiento de la investigación como destino de la donación de una muestra biológica sea inaceptable por cuanto no es lo mismo una investigación con fines universitarios que una con fines epidemiológicos emprendida por el Estado, una con fines antropológicos o forenses y otra con fines económicos dirigidos a obtener provecho comercial. Entonces resultará relevante saber qué se hará con esta parte del cuerpo, ahora material biológico, y así, por ejemplo, saber si se utilizará para propósitos comerciales una vez concluida la etapa de investigación académica y si eventualmente habrá algún beneficio para el individuo o la comunidad de la cual proviene. El problema radica en que resulta complejo en las primeras etapas de un desarrollo investigativo establecer claramente si habrá desarrollos empresariales o productos biotecnológicos generados a partir de ello.

Partiendo de un enfoque que articule la Bioética, la Genética y los Derechos Humanos $[45,46]$ se torna necesario plantear que ninguna medida será completamente «restitutiva» [47] debido a que cuando se dio a conocer la información referente a las células HeLa tanto su titular como la familia de esta perdieron toda posibilidad de preservar su intimidad [48]. Como consecuencia de lo sucedido, y aun cuando se intentara que no se siga divulgando información al respecto, sería imposible ahora poder restituir tanto a Henrietta como a su familia el anonimato previo. Si bien la comunidad científica pretendió reconocer los errores y vacíos que la técnica misma ha dejado en su paso buscando la dignificación de «la donante», cabe preguntarse si con la mera declamación de la dignidad de Henrietta Lacks, a modo de resarcimiento, alcanza para compensar el daño causado, o si es preciso reconocer que su información le pertenece y le incumbe tanto a ella como a sus familiares.

De allí la importancia de la incorporación de los comités de ética en el mundo científico, a quienes corresponde el abordaje ético de los problemas que se suscitan en el ámbito de la investigación y constituyen un espacio donde debe prevalecer una responsabilidad moral y sobre todo ética [49]. Como espacios ciudadanos constituidos para analizar las aristas posibles de la investigación sometida a su estudio, es función de los comités de ética abogar en casos de investigaciones con muestras biológicas para que se expliciten claramente el tipo de 
muestra biológica que se tomará, su utilización presente, indicando con precisión el objetivo de su obtención, así como su potencial uso futuro, aclarando cuál será el fin y por cuánto tiempo se almacenará dicha muestra. Si bien es cierto que en investigación estos aspectos son difíciles de definir, en muchas ocasiones se debiera actuar con prudencia y en todo caso evitando dañar a los otros. La Declaración Internacional sobre los Datos Genéticos Humanos de la UNESCO (2003) [37] hace referencia a este tema en los artículos 16 y 17, indica que los datos genéticos no se deberían usar con fines no autorizados expresamente en el consentimiento informado inicial.

Otro punto a tener en cuenta para casos similares es el derecho del donante o de su descendencia a no saber la información relevante identificada, ya que la misma condición patológica no siempre se manifiesta, sino que es correspondiente a la probabilidad de padecerla. Esto se contrapone con la necesidad de la comunidad científica y de la biomedicina de publicar los resultados de la investigación, lo que se debe hacer sobre información anonimizada; lo cual también se debe dejar constancia en el consentimiento informado. En el plano regulatorio la racionalidad jurídica busca la caracterización de una conducta ciudadana y frente a ella la penalización o sanción de su trasgresión, lo que requiere la legitimación social; sin embargo, en el caso de las células HeLa los resultados positivos, los éxitos reportados en la generación de los resultados y creación de empresas no parecía requerir consideración por la «eventual donante» (definida de esta manera por cuanto si hubiera sido debidamente consultada, lo que no ocurrió, es probable que hubiera donado sus células aún para fines distintos a los meramente diagnósticos), pues se asumió como un fenómeno similar o equivalente al de los hallazgos incidentales en la investigación.

Agradecer a Henrietta Lacks por su contribución a la ciencia médica, aunque esta no fue como tal, dado que nadie le informó que le serían extraídas sus células y que luego investigarían con ellas potenciales tratamientos para diversas enfermedades, resulta en extremo insuficiente, habiendo transcurrido ya más de sesenta años desde aquello y que al darse a conocer este tipo de prácticas también se develaron sus datos personales y sensibles, es decir, aquellos relacionados con sus características personales, individuales y privadas o íntimas según definición de la propia persona y su percepción de sí misma, con el consiguiente daño a su familia próxima y sus descendientes. Habiéndose constatado esa grave transgresión a la dignidad humana la búsqueda de una justicia real y efectiva se constituye en una responsabilidad social y un compromiso individual y colectivo, a fin de reparar en los hechos el daño causado, sin olvidar la responsabilidad que le atañe a la comunidad científica de corregir el posible daño en el presente y el futuro desarrollo de las investigaciones.

Si bien en los últimos años parecieran vislumbrarse resguardos éticos y legales, aún se requieren espacios de debate y deliberación en torno a los binomios universidad-empresa/institución investigadora y empresa-sociedad. La producción científica puede y, eventualmente, debe ser la base de empresas biotecnológicas nuevas que a su vez generen más empleo y movimiento de la economía, pero bajo ningún concepto, causa ni excepción se debe soslayar la dignidad de las personas en aras del mantenimiento de una lógica de mercado.

Asimismo, se deben revisar los criterios de patentamiento cuando la materia prima proviene de elementos vivos de la naturaleza, situación en la cual estamos más bien ante un descubrimiento y no ante un invento, siendo los derechos de propiedad sobre un descubrimiento 
objetables debido a que jurídicamente no se trata de una invención porque no existe «novedad». También es este un llamado de atención en cuanto a la posibilidad de discriminación o de cautividad que pudiere afectar a los portadores de características tan especiales como las de Henrietta Lacks, donde consideraciones en torno al respeto a la dignidad humana, a la integridad, intimidad y a la justicia merecen especial relevancia.

Por tal motivo, desde la perspectiva de la ética de la ciencia y la tecnología, y en un contexto regido por la incertidumbre es necesario enfatizar el principio general del respeto a la integridad personal para efectos de definir los cursos de acción orientados a la generación y a la gestión del conocimiento. En el caso de las células ya está visto su potencial de expresividad, sea natural o artificial, lo que llama, con justicia, a la necesidad de participar en la transferencia y el aprovechamiento compartido de la información bien sea con el donante o con la Humanidad, al entender que en ambos casos se trata de «material común a toda la especie». En este sentido, y atendida también la globalización, cobra actualidad la recomendación del Consejo Ejecutivo de la UNESCO para crear una Comisión Mundial de Ética de los Conocimientos Científicos y la Tecnología para «promover una reflexión ética, multidisciplinaria y multicultural sobre ciertos riesgos derivados del avance de la ciencia y la tecnología» [50]. No obstante, es preciso resaltar que, como lo indicó Bergel en 2014, «lamentablemente en este campo los intereses sectoriales son superiores a los principios jurídicos o a los fundamentos éticos» $[5 \mathrm{l}]$.

A fin de evitar vulnerabilidades futuras se torna necesario, aunque no suficiente, definir con claridad, exactitud y precisión los alcances y los límites de nociones tales como: «derecho de acceso a la historia clínica» individual y familiar, «derecho a controlar el uso de la información genética propia», "aprovechamiento compartido de los beneficios», "derecho de propiedad sobre los conocimientos obtenidos a partir del estudio de los genes humanos», entre otros.

\section{Conclusiones}

Toda esta reflexión nos lleva a proponer una constante deliberación en torno a la consideración de los seres humanos como sujetos sociales, relacionales e integrales. Es decir, no podemos separar el cuerpo biológico, con todas sus mínimas partes, del significado social de los individuos en constante relación con el otro o los otros. Es por esto que compartimos la premisa establecida por Paul Ricouer respecto al recto proceder y la recta acción que se da cuando consideramos al otro como nosotros mismos en instituciones justas, llámense estas organizaciones familiares, comunitarias o la misma comunidad científica en sus laboratorios [52]. La recta acción en ciencia entonces no es sólo el saber técnico con rigor, sino también el conocer la ciencia hecha por seres humanos para seres vivos con toda la consideración que ello implica. Esta reflexión invita también a que los estudiantes, profesores y en general investigadores conozcan las perspectivas jurídicas, éticas y sociales de la investigación desarrollada como proceso social con sus responsabilidades inherentes. 


\section{Bibliografía}

I. Álvarez JP. Henrietta lacks. el nombre detrás de las células hela, primera línea celular inmortal humana. Rev Med Clin Condes 2013; 24: 726-729.

2. Calvo S. Cultivo de células en 3D. La nueva dimensión de los cultivos celulares. CT 20 I3; 5: 21 5-232.

3. Caulfield T, McGuire AL. Policy uncertainty, sequencing, and cell lines. G3 (Bethesda) 20I3; 3: | 205- 1207.

4. Tavira-Montalván CA, Ortega-García A, DávilaGonzález I, Estrada-Mondaca S, Meneses-Acosta A. Alcances y perspectivas del cultivo de células animales en la biotecnología farmacéutica. Rev Mex Cienc Farm 2009; 40: 35-46.

5. Carrera-Páez LC, Pirajan-Quintero ID, UrreaSuarez MC, Sanchez-Mora RM, Gómez-Jiménez M, Monroy-Cano LA. Comparación del cultivo celular de HeLa y HEp-2: Perspectivas de estudios con Chlamydia trachomatis. Nova 20 I5; 13: 17-29.

6. Berlinguer G. Ciência, mercado e patentes do DNA humano. Capa 2000; 8: 97- 106.

7. Fuentes-Alburo A, Ochoa-Carrillo FJ. Recordando a Henrietta Lacks (HeLa). GAMO 20I I; I0: 249 251.

8. Silver M. A New Chapter in the Immortal Life of Henrietta Lacks. National Geographic. 2013. Disponible: http://news.nationalgeographic.com/ news/20 | 3/08/ | 308 | 6-henrietta-lacks-immortallife-hela-cells-genome-rebecca-skloot-nih/. Consultado: diciembre 2015 .

9. Bergel SD. Aspectos éticos y jurídicos de la comercialización de partes separadas del cuerpo humano. Rev Bioét 2013; 21: 199-206.

10. Senior A. Haunted by Henrietta: The Archive, Immortality and the Biological Arts. Contemp Theatre Rev 20। I; 21: 51 I-529.

II. Blatt RJR. Banking Biological Collections: Data Warehousing, Data Mining, and Data Dilemmas in Genomics and Global Health Policy. Community Genet 2000; 3: 204-211.

12. Organización Mundial de la Salud, Consejo de Organizaciones Internacionales de las Ciencias Médicas (CIOMS). Pautas Éticas Internacionales para la Investigación Biomédica en Seres Humanos. Ginebra, Suiza. 2002. Disponible: http://www.cioms. ch/publications/guidelines/pautas_eticas_internacionales.htm. Consultado: diciembre 2015.

13. Bergel SD. Bioética, cuerpo y mercado. Rev Col Bioética 2007; 2: 133-164.

14. Angell $M$. Is academic medicine for sale? $N$ Engl J Med 2000; 342: 1516-1518.

15. Bargardi D. Ciencia y Sociedad. Una mirada desde la ética. Cuadernos FHyCS-UNJu 2002; I5: 175 180.
16. Asociación Médica Mundial. Declaración de Lisboa de la AMM sobre los Derechos del Paciente. 2015. Disponible: http://www.wma.net/ es/30publications/IOpolicies/14/. Consultado: diciembre 2015

17. Flores-Guerrero R. Salud, Enfermedad y Muertes: Lecturas desde la Antropología Sociocultural. Revista Mad 2004; 10: I-8.

18. Asociación Médica Mundial. Código Internacional de Etica Médica. 1994. Disponible: http://www. wma.net/es/30publications/I Opolicies/c8/index. html.pdf?print-media-type\&footer-right=[page]/[toPage. Consultado: diciembre 2015.

19. Gibert-Galassi J. Hugh Lacey, Valores e atividade científica I. Atenea (Concepc) 2013; 507: 222-224.

20. Bota i Arqué A. El reto de la muestra biológica en los estudios farmacogenéticos. Acta Bioeth 2004; 10: $201-212$

21. Andorno R. La dignidad humana como noción clave en la Declaración de la UNESCO sobre el genoma humano. Rev Derecho Genoma Hum 200 I; I 4: 4I-53.

22. UNESCO. Declaración universal sobre Bioética y Derechos Humanos. 2005. Disponible: http://portal.unesco.org/es/ev.php-URL_ID=3 I 058\&URL_ DO=DO_TOPIC\&URL_SECTION=20l.html. Consultado: diciembre 2015.

23. Hoyos G. Estructuración del discurso bioético. Comunicación y lenguaje. En: Garrafa $\vee$, Kottow M, Saada $A$, eds. Estatuto epistemológico de la bioética. México: UNESCO. Universidad Nacional Autónoma de México, Instituto de Investigaciones Jurídicas; 2005: 193-218

24. Martínez-Barreiro A. La construcción social del cuerpo en las sociedades contemporáneas. Pap Rev Sociol 2004; 73: 127-152.

25. Gómez-Córdoba Al. Principios éticos y jurídicos del derecho genético en las declaraciones internacionales relacionadas con las intervenciones sobre el genoma humano. Vniversitas 20 I0; 120: I4 I- 167.

26. Vergès de López $C$, Sotomayor MA, López Dávila LM, Sorokin P. Conflictos de interés: El «caso Olivieri». En: Álvarez-Díaz JA, López-Moreno S, eds. Ensayos sobre ética de la salud: Aspectos Clínicos y Biomédicos Vol. 2. México D.F., México: Universidad Autonóma Metropolitana. Unidad Xochimilco; 2014: 43-60

27. Thompson DF. Understanding financial conflicts of interest. N Engl J Med 1993; 329: 573-576.

28. Zalaquett J. Conflictos de intereses: normas y conceptos. Anuario DDHH 20। I; 7: 179-189.

29. Digilio P. Transformaciones en la construcción de la noción de riesgo social a partir de los desarrollos en el campo de la genética. IV Jornadas Nacionales 
de Debate Interdisciplinario en Salud y Población, Agosto 8-10. Buenos Aires, Argentina: Instituto de Investigaciones Gino Germani, Facultad de Ciencias Sociales, Universidad de Buenos Aires; 2001.

30. Masters JR. HeLa cells 50 years on: the good, the bad and the ugly. Nat Rev Cancer 2002; 2: 315-319.

31. Keyeux G. Bancos de datos genéticos humanos: el equilibrio vacilante entre ciencia y derechos humanos. En: Penchaszadeh VB, ed. Genética y Derechos Humanos: Encuentros y Desencuentros. Buenos Aires, Argentina: Biblioteca Nacional-Editorial Paidós; 2012: 237-262.

32. UNESCO. Declaración Universal sobre el Genoma Humano y los Derechos Humanos. 1997. Disponible: http://portal.unesco.org/es/ev.phpURL_ID = 3 | 77\% \&URL_DO=DO_TOPIC\&URL_ SECTION=20 I.html. Consultado: diciembre 2015.

33. Mainetti JA. Código de Núremberg, Tribunal Internacional de Núremberg, 1948. En: Ética médica. La Plata, Argentina: Editorial Quirón; 1989.

34. Organización de las Naciones Unidas (ONU). Declaración Universal de Derechos del Hombre. 1948. Disponible: https://documents-dds-ny.un.org/ doc/RESOLUTION/GEN/NR0/046/82/IMG/ NR004682.pdf?OpenElement. Consultado: diciembre 2015.

35. Organización de las Naciones Unidas (ONU). Declaración de las Naciones Unidas sobre la Clonación Humana 2005. Disponible: https://documentsdds-ny.un.org/doc/UNDOC/GEN/N04/493/09/ PDF/N0449309.pdf?OpenElement. Consultado: diciembre 2015.

36. Organización de las Naciones Unidas (ONU). Convenio sobre la Diversidad Biológica; 1992.

37. UNESCO. Declaración Internacional sobre los Datos Genéticos Humanos. 2003. Disponible: http://portal.unesco.org/es/ev.php-URL

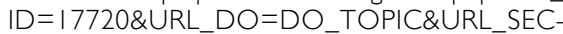
TION=20l.html. Consultado: diciembre 20I5.

38. UNESCO. Declaración sobre la Ciencia y el uso del saber científico. 1999. Disponible: http://www. unesco.org/science/wcs/esp/declaracion_s.htm. Consultado: diciembre 2015.

39. UNESCO. Declaración Universal de la UNESCO sobre la Diversidad Cultural. 2001. Disponible: http://portal.unesco.org/es/ev.php-URL_

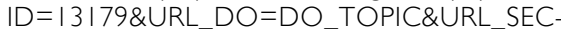
$\mathrm{TION}=20 \mathrm{I} . \mathrm{html}$. Consultado: diciembre 2015 .

40. UNESCO. Declaración sobre las Responsabilidades de las Generaciones Actuales para con las Generaciones Futuras. 1997. Disponible: http://portal. unesco.org/es/ev.php-URL_ID=|3178\&URL_
DO=DO_TOPIC\&URL_SECTION=20 I.html. Consultado: diciembre 2015.

4I. Asociación Médica Mundial. Declaración de la AMM sobre el Proyecto Genoma Humano. 1992. Disponible: http://www.wma.net/es/30publications /IOpolicies/20archives/g6/. Consultado: diciembre 2015.

42. Asociación Médica Mundial. Declaración de Helsinki de la AMM - Principios éticos para las investigaciones médicas en seres humanos. 2013. Disponible: http://www.wma.net/es/30publications/IOpolicies/ b3/. Consultado: diciembre 2015.

43. Sociedad Internacional de Bioética. Declaración Bioética de Gijón. 2000. Disponible: http://www. sibi.org/es/ / 2-declaraciones/68-declaracion-bioetica-de-gijon.html. Consultado: diciembre 2015.

44. Varsavsky O. Ciencia, política y cientificismo. Buenos Aires, Argentina: Centro Editor de América Latina; 1969.

45. Bergel SD. El vínculo de la genética con los derechos humanos. En: Penchaszadeh VB, ed. Genética y Derechos Humanos: Encuentros y Desencuentros. Buenos Aires, Argentina: Biblioteca NacionalEditorial Paidós; 2012: 41-68.

46. Bergel SD. La declaración universal de la UNESCO sobre el genoma humano y los derechos humanos. Cuad Bioet 1998; 34: 387-405.

47. Caplan A. NIH finally makes good with Henrietta Lacks' family -- and it's about time, ethicist says. 20 I3. Disponible: http://www.nbcnews.com/health/ nih-finally-makes-good-henrietta-lacks-family-itsabout-time-6Cl086794I. Consultado: diciembre 2015.

48. Pfeiffer ML. Bioética y derechos humanos: una relación necesaria. RevRedbioética/UNESCO 201 I; 2: 74-84.

49. Mondragón-Barrios L. Elementos circundantes a los comités de ética que dificultan su razonamiento deliberativo. Acta Bioeth 2013; 19: 285-292.

50. UNESCO. Actas de la 29a reunión de la Conferencia General. Paris, Francia. 1997. Disponible: http:// unesdoc.unesco.org/images/00 | |/00 | | 20/ | | 2020s. pdf. Consultado: diciembre 2015.

5I. Bergel SD. Enfoque ético-jurídico de la sentencia de la Corte Suprema de los Estados Unidos sobre patentabilidad de genes humanos. Rev Bioét 2014; 22: 18-27.

52. Alzate Mejía NA. Aportes de la hermenéutica ricoeuriana a la bioética. Trabajo de Grado para optar al título de Magister en Bioética. Bogotá D.C., Colombia: Instituto de Bioética, Pontificia Universidad Javeriana; 201 I. 


\section{$\pi$ Laboratorio or Clínico \\ Y Hematológico}

Creemos en los sueños de todos los colombianos que llevan en la sängre confianza

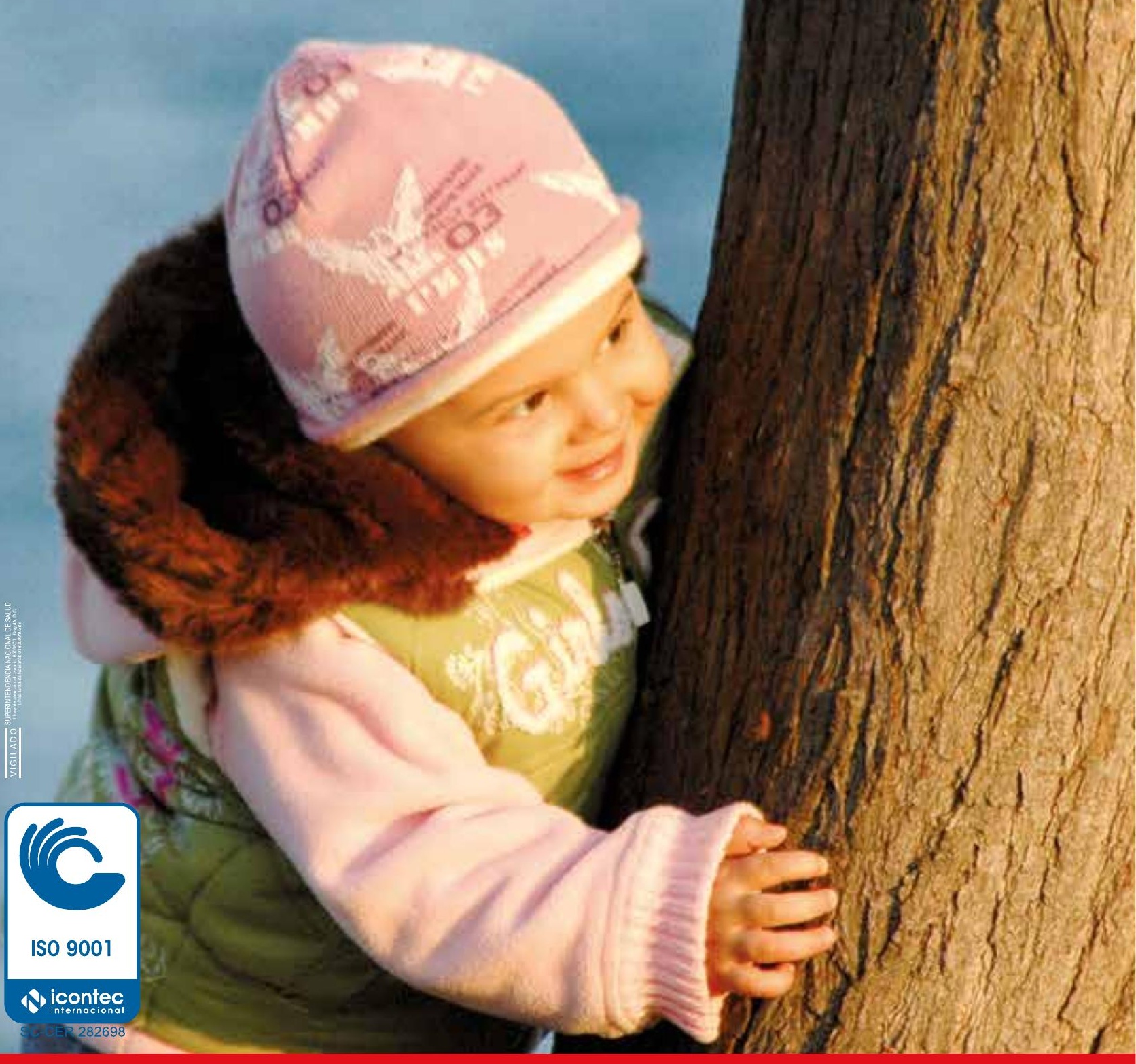

Sede Principal Poblado: Carrera 43C No. 5-33

Toma de Muestras: Centro Comercial Sandiego, Torre Norte, Piso 10, No. 1034 